\title{
Serum Levels of Selenium, Zinc, Copper and Magnesium in Asthmatic Patients: a Case Control Study.
}

\author{
Magboula Mamoun Hussein ${ }^{1}$, Allaadin Ahmad Yousif ${ }^{2}$, and Amal Mahmoud Saeed. ${ }^{3}$
}

\begin{abstract}
:
Background: Free radicals have harmful effects on cells and tissues and are thought to be responsible for the pathogenesis of many diseases including bronchial asthma. Selenium (Se), Zinc $(\mathrm{Zn})$, copper $(\mathrm{Cu})$, and magnesium $(\mathrm{Mg})$ are trace elements required for the antioxidant enzymes and hence the optimal functions of the immune system. Changes in the levels of these elements may lead to a reduction in antioxidant activities in asthma.

Objective: This study was conducted to determine serum levels of the trace elements $\mathrm{Se}, \mathrm{Zn}, \mathrm{Cu}$, and $\mathrm{Mg}$ in asthmatic patients in order to evaluate the associations of these nutrients with asthma in adults
\end{abstract}

Subjects and Methods: Serum $\mathrm{Se}, \mathrm{Zn}, \mathrm{Cu}$, and $\mathrm{Mg}$ concentrations were measured in 100 asthmatic adult patients and 170 healthy control subjects matched for age and sex. The patients were recruited from asthma casualties, referred clinics and wards of Elshaab and Omdurman Teaching Hospital, Khartoum Sudan.

Socio- demographic data and clinical history of all subjects were collected in questionnaires.

Results: Serum Se and $\mathrm{Cu}$ levels were found to be significantly decreased in asthmatic patients compared to controls. Mean serum $\mathrm{Se}$ and $\mathrm{Cu}$ for patients were $65.8 \pm 5.5 \mu \mathrm{g} / 1$ (mean $\pm \mathrm{SD})$ and $0.711 \pm 0.37 \mathrm{~g} / 1$ respectively while that for controls were $78.2 \pm 7.5 \mu \mathrm{g} / 1$ and $0.939 \pm 0.322 \mathrm{~g} / 1$ respectively (P value was $<$ 0.001). On the other hand the mean serum $\mathrm{Zn}$ level was significantly higher in patients compared to controls $(1.2 \pm 0.51 \mathrm{~g} / 1$ and $0.94 \pm 0.254 \mathrm{~g} / 1$ respectively) (P value was $<0.001)$. No significant difference was found in the mean serum Mg level between patients and controls $(16.4 \pm 4.2 \mathrm{~g} / \mathrm{l}$ and $16.3 \pm 2.89 \mathrm{~g} / \mathrm{l})(\mathrm{P}$ value was $0.825)$.

Conclusions: The observed changes in the levels of the trace elements which were a decrease in serum copper and selenium and an increase in zinc may affect the antioxidant enzymes' functions, and decrease the antioxidant capacity in asthma.

Key words: antioxidant, immune, micronutrients.

$\mathrm{N}$ utrition represents an important conditioning factor of many cardiovascular, gastrointestinal and pulmonary chronic diseases ${ }^{1}$.

Trace elements are essential micronutrients that exist in very low concentrations in the body, forming $0.01 \%$ of the total body weight $^{2}$. They play an important role in various physiological processes, and are crucial for proper functioning of the immune system. Deficiency of trace elements and infectious diseases are often concomitantly observed and result in complex interactions ${ }^{3}$.

1-Khartoum college of medical sciences.

2-Department of internal medicine, Fauclty of Medicine, University of Khartoum Sudan

3-.Department of Physiology, Faculty of Medicine,

University of Khartoum. Sudan
The major trace elements such as selenium, zinc, copper, and magnesium have imunomodulatory effects and thus influence susceptibility and the course of a variety of infections. This is mainly due to the fact that these elements are part of the structure of antioxidant enzymes. These enzymes act as antioxidant defense and are able to regulate the host immune system, and alter viral genome ${ }^{3}$.There is increasing evidence that reactive oxygen species can be of particular importance in the pathophysiology of several lung diseases ${ }^{4}$.

The antioxidant mechanisms that protect the lung against these oxidants include: three superoxide dismutases (SODs) and Glutathione peroxidase (GSH-Px) $)^{4}$. GSH-Px has selenium and the super oxide dismutases have copper and zinc in their structure. 
Changes in the level of these trace elements decrease the efficiency of antioxidant systems and this leads to hyper-reactivity and inflammation in the respiratory tract ${ }^{5}$.

Objective: This study was conducted to determine serum levels of the trace elements $\mathrm{Se}, \mathrm{Zn}, \mathrm{Cu}$, and $\mathrm{Mg}$ in asthmatic patients in order to evaluate the associations of these nutrients with asthma in adults

\section{Materials and Methods:}

\section{Subjects:}

Patients: The study included 100 patients with bronchial asthma 47 of them were females. The ages of patients ranged from 2065 years. They were randomly selected from patients followed up by the Department of Pulmonary Diseases of ElShaab and Omdurman Teaching Hospitals Khartoum Sudan. All patients were previously diagnosed as asthmatics. None of the patients had diabetes mellitus, liver or kidney diseases, infection or thyroid dysfunction.

Controls: 170 healthy adults of both genders matched for sex and age. They were either copatients or living in the same areas of patients sharing the same life style.

\section{Methods:}

Socio-demographic data and clinical history were obtained from patients and controls using questionnaires

Laboratory investigations: Venous blood samples were taken from subjects in the morning. Serum was separated and collected in Eppendorf tubes and stored at $-20^{\circ} \mathrm{C}$ for the measurement of selenium, copper, zinc and magnesium.

Serum selenium level was determined by atomic absorption spectrometer equipped with a graphite furnace atomizer and an auto sampler (Varian Spectr. AA220) ${ }^{6}$.

Serum level determination of $\mathrm{Zn}, \mathrm{Cu}$ and $\mathrm{Mg}$ had been carried out using a flame atomic absorption spectrometer (Varian SpectrAA). The calibration graphs were constructed applying normal aqueous standards ${ }^{6}$.

Statistical Analysis: Mean and standard deviation of all parameters in serum were calculated. Students' t-test was used for comparison of means and $\mathrm{P}<0.05$ was considered significant.

\section{Results:}

All patients were diagnosed as asthmatics. The frequency for less than 10 years duration of asthma was 45\%, 10-19 years duration was $33 \%$ and 20 years or more was $22 \%$. They all had a history of intermittent wheezing, shortness of breath, chest tightness and were taking different asthma medications.

Serum zinc concentration was found significantly higher in patients compared to controls, $(1.201 \pm 0.51 \mathrm{~g} / 1$ and $.948 \pm 0.254 \mathrm{~g} / 1$ respectively), $\mathrm{P}$ value was 0.001 (figure 1).

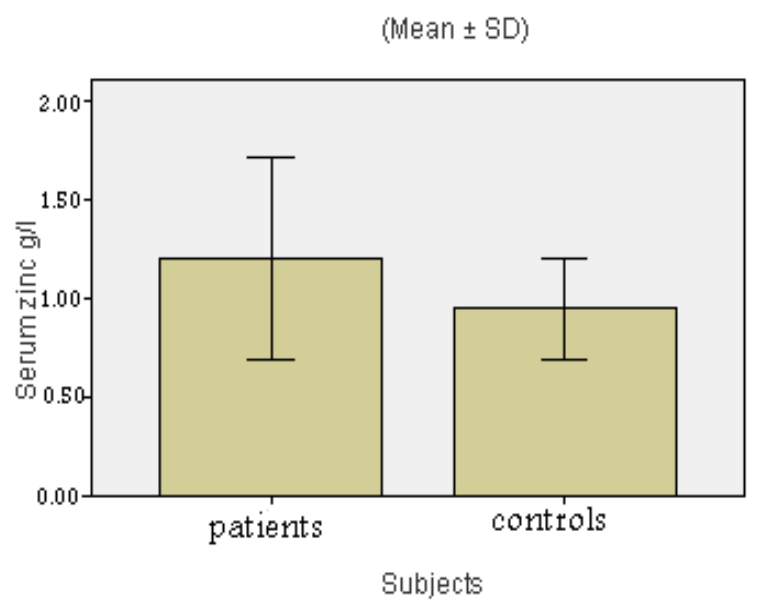

Fig. 1: serum zinc concentrations in patients and controls

There was no significant difference in the mean magnesium level between the patients and control group $(16.44 \pm 4.27 \mathrm{~g} / 1$ and 16.34 $\pm 2.89 \mathrm{~g} / 1$ respectively), $\mathrm{p}$ value was 0.825 (figure 2).

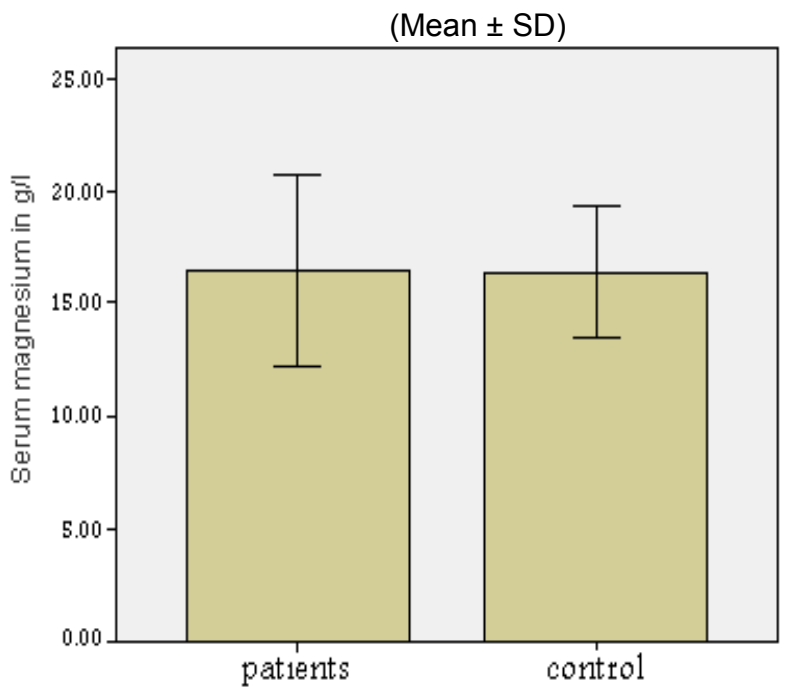

Fig 2: serum magnesium concentration

The mean concentrations of copper were found to be significantly lower in patients 
compared to controls, $(.699 \pm 0.37 \mathrm{~g} /$ land .939 $\pm .322 \mathrm{~g} / \mathrm{l}, \mathrm{P}$ value was 0.0001 (figure 3 ).

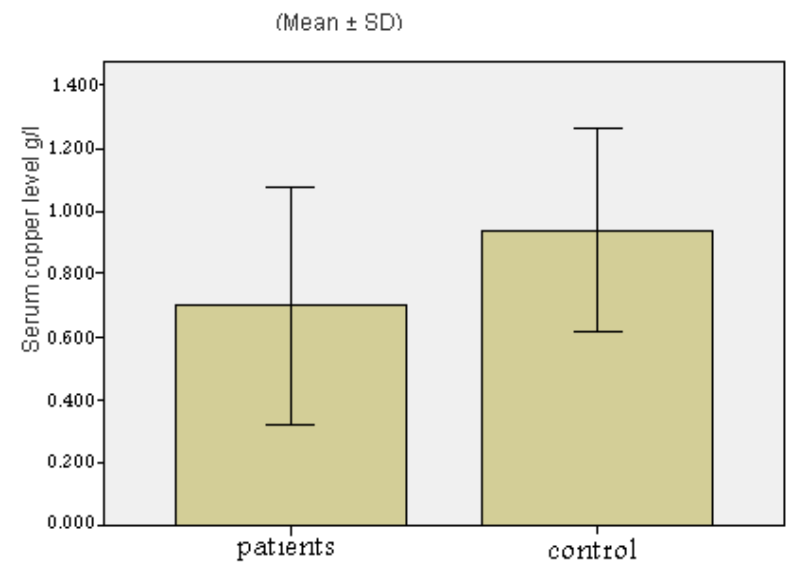

Fig.3: serum copper concentratios in patients and controls Serum concentrations of selenium were found to be significantly lower in patients compared to controls, $65.8 \pm 5.5 \mu \mathrm{g} / 1$ and $78.2 \pm 7.5 \mu \mathrm{g} / 1$ respectively, $\mathrm{P}$ values were 0.001 (Figure 4 ).

(Mean +/. SD)

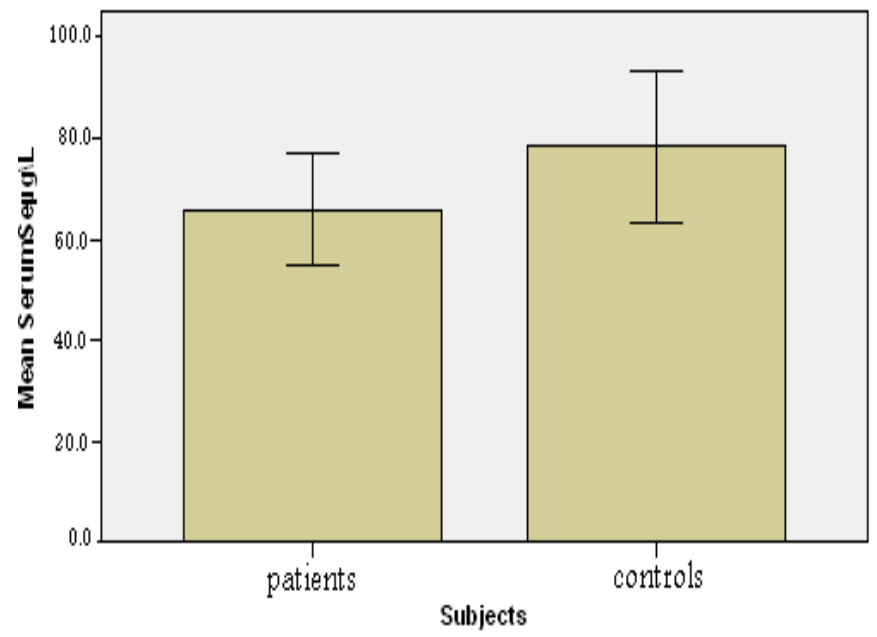

Fig.4: serum selenium concentration

A negative significant correlation was found between serum copper and zinc levels in patients, $(\mathrm{r}=-.148, \mathrm{p}$ value was0.01). No correlations were found between the level of these elements and age or sex.

\section{Discussion and conclusions:}

Following the understanding of the role of free oxygen radicals in pathogenesis of asthma, most studies have recently paid attention to the role of antioxidant defense systems. The most important antioxidant systems are the SODs and the GSH-Px which contain zinc/ copper and selenium in their structures respectively.
In the current study, serum zinc was found to be elevated while serum copper levels were lowered in the patients. There are controversial reports regarding changes in serum level of zinc and $\mathrm{Cu}$ in asthma. It was reported that serum zinc concentrations decreased, and serum copper concentrations increased in asthmatics and the $\mathrm{Zn} / \mathrm{Cu}$ ratio were decreased ${ }^{7-10}$. WHIG in1995 found that unlike copper, serum zinc levels were significantly low in patients than in controls ${ }^{11}$. On the other hand, elsewhere increased serum levels of zinc were found in severe cases of asthma $^{12}$ which agrees with the findings of the current study. Both copper and zinc were reported in other studies not to be significantly different in asthmatic patients and controls, but copper levels were significantly higher in female asthmatics than in males ${ }^{13}$.

Little data on the intake and the influence of either the severity of the disease or its treatment on the plasma levels of these trace elements are available. These factors may explain the variations in the findings of the previous reports. In a novel study which characterized the elemental composition of exhaled breath condensate (EBC) in order to identify new biomarkers of exposure and susceptibility in asthmatic patients, reduced EBC copper levels in asthmatics were obtained. EBC copper levels in COPD patients may be of particular interest, because of the positive correlation with lung function parameters. Low copper may also be associated with a reduction of SOD expression and activity ${ }^{14}$.

As both metals $\mathrm{Zn}$ and $\mathrm{Cu}$ form the prosthetic group of SOD, any alteration in their levels affect the activity of the enzyme. Decrease in this element impairs the enzyme activity. Such a condition may cause oxidative stress or may further increase an existing stress ${ }^{9}$. The negative correlation of copper and zinc may be explained by their competition either for the same absorptive binding sites on the intestinal mucosal cells or for similar functional protein systems ${ }^{15}$.

Epidemiological evidence suggests that a low dietary intake of magnesium is associated 
with impaired lung function, bronchial hyper reactivity, and wheezing. It was found that a high magnesium intake is associated with improvement in symptom score, though not in objective measures of air flow or airway reactivity in stable asthmatic subjects. When given intravenously magnesium can lead to broncho- dilatation in acute severe asthma ${ }^{16}$. No difference in serum level concentrations between asthmatics and controls was obtained in this study. This result was similar to some reports in the litreature ${ }^{8,9,17}$ and differ from other ones ${ }^{13}$.

Selenium is a key component of a number of functional selenoproteins like GSH-Px, which reduces hydrogen peroxidase and other organic peroxides to nontoxic substances ${ }^{17}$, thus reduced levels of this trace element may potentially lead to reduced activity of GSH$P x$ and decreased antioxidant defense mechanisms ${ }^{17}$.

Studies performed to determine a possible relationship between Se levels and asthma had yielded contradictory results.

Serum Se values of $100 \mu \mathrm{g} / \mathrm{L}$ are recommended for optimal activity of GSH$\mathrm{Px}^{18}$. Current values of our study were considerably below this threshold even for controls. This may be due to decrease of Se intakes as a result of low soil content of $\mathrm{Se}^{19}$. Nevertheless, serum Se was significantly decreased in asthmatics when compared to controls. This agrees with the findings reported before ${ }^{20-25}$.

In conclusion, this preliminary study suggests that low Se and $\mathrm{Cu}$ levels may have a role in bronchial asthma in Sudan. Replacement of these nutrients may prove beneficial in decreasing the incidence of bronchial asthma and its progression.

\section{References:}

1. D O'razio G R N. The role of selenium, zinc, and antioxidant vitamin supplementation in the treatment of bronchial asthma: adjuvant therapy or not? Expert opinion on investigational drugs 2005; 14(9):1145-1155.

2. Laker M. On determining trace element level in man:The uses of blood and hair. The Lancet 1982; 31:260-262.

3. Lukac N, Massanji P. Effects of trace elements in the immune system. Epidemiol Microbiol Immunol 2007; 56(1): 3-9.

4. Vuokko L, Kinnula James D, Craps. Superoxide dismutase. American journal of respiration and critical care medicine 2003; 167: 1600-161
5. Pucheu S, Coudray C, Tresallet N et al. Effect of dietary antioxidants trace elements supply on cardiac tolerance to ischemia reperfusion in rat. $\mathrm{J}$ Mol Cell Cardicol 1995; 27: 2303-14.

6. Fernandez FJ, Kahan HL. Clinical methodology for atomic absorption spectroscopy. Clin Chem 1971; 3:24.

7. EL-Kholy MS, Gas Allah MA., ELshimi S et al. Zinc and copper status in children with bronchial asthma and atopic dermatitis. J Egypt Public Health Assoc 1990; 65:657-668.

8. Ermis B, Armutcu F, Gurel A et al. Trace elements status in children with bronchial asthma. Europian Journal of General Medicine 2004; 1 (1): 4-8.

9. Vural H, Uzun K, Uz E et al. Concentrations of copper, zinc and various elements in serum of patients with bronchial asthma. J Trace Elem Med Biol. 2000; 14(2):88-91.

10. Kadrabova J, Madari C, Podivinsky F et al. Plasma zinc, copper and copper/zinc ratio in intrinsic asthma. J Trace Elem Med Biol 1996;10:50-53.

11. Whig J, Naranga PS, Goyal S C et al. Serum zinc and copper levels in asthma. Trace elements and electrolytes 1995; 12(4):198-199.

12. Lurina TM, Kupriianova TA, Chereiskaia NK, et al. Macro- and micro trace element of blood in elderly patients with bronchial asthma. Klin Med Mosk 2002; 80(11):30-4.

13. Anetor JI, Ajose OA, Ige O et al. Antioxidant status of adult Nigerian asthmatics: implication for prognosis. Nutr Health 2003; 17 (3): 221-9..

14. Antonio M, Massimo C, Matteo G et al. Exhaled Metallic Elements and serum Pneumoproteins in Asymptomatic Smokers and Patients with COPD or Asthma. Chest 2006;129:1288-1297.

15. Evans GW, Hahn CJ. Copper and Zinc binding components in rat intestine. Adv Exp Biol 1974;48:285297., 16. Hill J, Mickl E A, Lewis S et al. Investigation of the effect of short term change in dietary magnesium intake in asthma. Eur Respir J 1996;10:6:2225-2229.

17. Picado C, Eulofeu R, Lloonart $\mathrm{R}$ et al. Dietary micronutrients/antioxidants and their relationship with bronchial asthma severity. Allergy 2001; 56(1):56.

18. Thomson CD, Robinson MF, Butler JA et al. Long term supplementation with selenate and selenomethionine: selenium and glutathione peroxidase (EC 1.11.1.9) in blood components of New Zealand women. Br J Nutr1993; 69: 577-88.

19. Mokhtar M, Al Askar E, Elkholy O. Does selenium deficiency have a role in cardiovascular diseases in Egypt? Egypt Heart J 2006; 58(4): 649-653.

20. Misso NL, Powers KA, Gillon RL et al. Reduced platelet glutathione peroxidase activity and serum selenium concentration in atopic asthmatic patients. Clin Exp Allergy 1996; 26(7):838-47.

21 Flatt A, Pearce N, Thomson CD et al. Reduced asthmatic subjects in New Zealand. Thorax 1990: 45: 95-99.

22. Fogarty A, Britton J. The role of diet in the aetiology of asthma. Clin Exp Allergy 2000; 30: 615-627.

23. Shaheen SO, Sterne JA, Thompson RL et al. Dietary antioxidants and asthma in adults: population-based case control study. Am J Respir Crit Care Med 2001; 164: 18231828.

24. Qujeq D, Hidari B, Bijani K et al. Glutathione peroxidase activity and serum selenium concentration in intrinsic asthmatic patients. Clin Chem Lab Med 2003: 41(2):200-2.

25. Rachel N, Rubin, Livia N et al. Relationship of Serum Antioxidants to asthma prevalence in Youth. American Journal of Respiratory and Critical Care Medicine 2004; 196: 393-398. 